\title{
Autonomia, empreendedorismo e competitividade: a universidade na trilha do future-se
}

\author{
Autonomy, entrepreneurship and competitivity: \\ university on the future-se program trail \\ Autonomia, empreendedorismo y competitividad: \\ la universidad en el camino del future-se
}

\author{
ANA PAULA RIBEIRO DE SOUSA \\ https://orcid.org/0000-0002-0500-0179 \\ Universidade Federal do Maranhão \\ Departamento de Educação \\ Maranhão, MA, Brasil \\ LEONARDO JOSÉ PINHO COIMBRA \\ https://orcid.org/0000-0001-6216-800X \\ Universidade Federal do Maranhão \\ Departamento de Educação \\ Maranhão, MA, Brasil
}

Resumo: $\mathrm{O}$ artigo analisa como as diretrizes e eixos fundamentais do Programa Future-se têm sido implementados na Universidade Federal do Maranhão por meio de algumas ações da atual gestão, fazendo com que a adesão ao projeto governamental ocorra de forma silenciosa e à revelia de um debate mais amplo com a comunidade acadêmica, contribuindo para o processo de refuncionalização da universidade. O estudo é ancorado no método histórico-dialético e foi realizado a partir de pesquisa bibliográfica, documental e de levantamento de dados e informações sobre a IES pesquisada.

Palavras-chave: Future-se. UFMA. Universidade. Refuncionalização.

\begin{abstract}
The article analyzes how the guidelines and fundamental axes of the Future-se Program have been implemented at the Federal University of Maranhão through some actions of the current management, making adherence to the government project occur silently and in spite of a broader debate with the academic community, contributing to the university's repurpose process. The study is anchored in the historical-dialectical method and was carried out based on bibliographic, documentary research and data and information survey on the researched institution
\end{abstract}

Keywords: Future-se. UFMA. University. Repurpose. 
Resumen: El articulo analiza como las directrices y ejes fundamentales del Programa Futurese ha sido implementado en la Universidad Federal de Maranbão a través de algunas acciones de la actual gestión, haciendo con que la adhesión al proyecto gubernamental ocurra de forma silenciosa y a la contumacia de un debate más amplio con la comunidad académica, contribuyendo para el proceso de refuncionalización de la Universidad. El estudio está anclado en el método bistórico-dialéctico y fue realizado a partir de investigación bibliográfica, documental y de levante de datos e informaciones sobre la IES investigada.

Palabras clave: Future-se. UFMA. Universidad. Refuncionalización.

\section{INTRODUÇÃO}

Nos últimos anos, temos visto se intensificar a agenda de desmontes do patrimônio público, de desresponsabilização do Estado pela manutenção das políticas sociais, das medidas de restrições dos gastos públicos e de reformas que atacam frontalmente os direitos da população ${ }^{1}$.

O governo de Jair Bolsonaro já demonstrou grande entusiasmo e potencial para dar continuidade às reformas estruturais que aprofundam a ortodoxia neoliberal, como a aprovação da reforma da previdência (EC n ${ }^{\circ}$ 06/2019), alterações na legislação trabalhista, o projeto de reforma administrativa (PEC 32/2020), programa de desestatização das empresas públicas, além de outras medidas que, se aprovadas, representam um grande risco à manutenção dos serviços públicos nas esferas federal, estadual e municipal.

No âmbito da educação superior, o governo federal, adotando um discurso anti-intelectualista, anticientífico e privatista voltou seus ataques contra as universidades federais, inicialmente com o contingenciamento de recursos ${ }^{2}$, sob o argumento de que estas não são produtivas e que desperdiçam o recurso público com "balbúrdia", ao invés de cumprirem sua função, que, sob a ótica do Ministério da Educação (MEC), reduz-se a produzir "resultados" e alcançar índices em avaliações oficiais e rankings internacionais.

Contrariando esse discurso, as universidades públicas são responsáveis pela produção de conhecimento científico relevante e de quase toda a pesquisa produzida no país, além de serem as instituições mais bem avaliadas pelo próprio MEC. Então, o que justifica essa postura? Por certo, a universidade pública, no cumprimento de sua função, aponta, por meio da pesquisa, do ensino e da

$1 \quad$ Entre as medidas, nesse sentido, tomadas pelo governo Michel Temer, entre 2016 e 2018, cita-se: a lei $n^{\circ} 13.467 / 2017$, que aprova a reforma trabalhista; a emenda constitucional $n^{\circ} 95$, de dezembro de 2016, que congela os gastos públicos por 20 anos; a PEC 287/2016, que dispõe sobre a reforma da previdência.

2 O contingenciamento de 30\% das verbas discricionárias anunciado em maio de 2019 pelo MEC atingiu de forma diferenciada as IFES. De acordo com levantamento da Andifes, o contingenciamento aplicado varia de 50 a 15\% das receitas discricionárias das IFES. Ver em: http://www.agenciabrasil.ebc.com.br/educacao/ noticia/2019-05/andifes-bloqueio-universidades-e-de-54-de-verbas-discricionarias. Acesso em: maio 2020.

1054 • Rev. Bras. Polít. Adm. Educ. - v. 37, n. 2, p. 1053 - 1070, mai./ago. 2021 
extensão e do rigor na análise, as contradições da realidade social de forma crítica e qualificada, representando uma importante linha de resistência ao atual governo. Isso reforça ainda mais os ataques direcionados à essas instituições, com o suposto discurso de combater a doutrinação ideológica.

Por esse motivo, devem ser cada vez mais asfixiadas ou reduzidas a agências de produção de resultados a favor do mercado, seja por meio de produtos e processos que atendam as demandas do setor produtivo, seja através da formação de sujeitos com uma mentalidade empreendedora e flexível, totalmente alinhada à atual racionalidade neoliberal (DARDOT; LAVAL, 2016) ${ }^{3}$. Esse nexo parece permear todo o discurso em torno da refuncionalização das universidades e institutos federais materializado no programa "Future-se: construindo universidades empreendedoras e inovadoras".

O presente artigo tem por objetivo analisar, em linhas gerais, como esse programa pretende realizar a refuncionalização das universidades federais, tornando-as mais "competitivas e inovadoras" e, a partir de um caso concreto, o da Universidade Federal do Maranhão (UFMA), demostrar como essas diretrizes têm sido abraçadas pelos gestores, que, mesmo sem aprovação do Future-se, começam a implementá-lo na prática, de forma silenciosa e à revelia de um debate mais amplo com a comunidade acadêmica.

O texto está estruturado em três seções. A primeira visa uma breve caracterização do Programa Future-se, abordando desde sua sistematização inicial até a versão final, encaminhada como projeto de lei ao Legislativo federal. $\mathrm{Na}$ segunda seção, são analisados elementos que sugerem uma aproximação da UFMA aos princípios e objetivos do programa, por meio da análise de algumas medidas implementadas pela atual gestão da universidade. Conclui-se que, apesar de ainda não ter sido formalmente aprovado, os princípios e ideias que se consubstanciam no Future-se já se encontram presentes em nossas universidades, sinalizando um processo de reestruturação dessas instituições.

O método de análise utilizado foi o materialismo histórico-dialético, ancorado nas categorias de totalidade, historicidade, contradição e mediação (FRIGOTTTO, 2020). Como procedimentos de pesquisa, foram realizadas análises bibliográfica e documental. Os dados empíricos foram levantados por meio de documentos produzidos pela própria instituição de ensino superior (IES) e disponibilizados em seu site e por meio de informações solicitadas a setores da universidade. Estes foram tratados por meio de análise de conteúdo que, segundo Moraes (1999), consiste em uma metodologia de pesquisa utilizada na descrição

De acordo com os autores, o neoliberalismo é compreendido, fundamentalmente, como uma racionalidade que tem como principal característica a generalização da concorrência como norma de conduta e da empresa como modelo de subjetivação. Para os autores, o neoliberalismo é a razãa do capitalismo contemporâneo. 
e interpretação de documentos e textos que, por meio de análise sistemática, permite ao pesquisador reinterpretar mensagens e atingir uma compreensão mais profunda destas.

\section{O FUTURE-SE E O PROCESSO DE REFUNCIONALIZAÇÃO DAS UNIVERSIDADES FEDERAIS}

O Future-se foi lançado em 17 de julho de 2019 e visa a promover maior autonomia financeira nas universidades e institutos federais por meio de incentivo à captação de recursos próprios e ao empreendedorismo. Qualificado pelo MEC como inédito e inovador, o propõe uma mudança de cultura nas instituições públicas de ensino superior e maior autonomia financeira das universidades e institutos federais (IFs).

O programa já teve três versões apresentadas pelo MEC, entre julho e outubro de 2019, disponibilizadas em seu site para consulta pública e envio de sugestões. Apesar de mudanças apresentadas nas três versões, o programa mantém o fundamental: a necessidade de refuncionalização (LEHER, 2019) dos institutos federais de ensino superior (IFES) e IFs, tornando-os mais permeáveis as demandas do mercado ${ }^{4}$, reduzindo, ainda mais, sua autonomia.

De maneira geral, podemos afirmar que a $2^{a}$ e a $3^{a}$ versões do programa apontam modificações mais significativas em relação à primeira, como o aperfeiçoamento de técnica jurídica, fazendo referência à aplicação de dispositivos da legislação já existente. Houve também a retirada de temas mais polêmicos, como a adoção de mecanismos de governança, semelhantes ao modelo corporativo, a obrigação de reduzir despesas com pessoal, a bonificação salarial aos servidores, a previsão de um Comitê Gestor externo e a substituição do termo "adesão” por "contratualização", e a inclusão de referências às fundações de apoio.

A figura dos fundos é mantida nas duas versões, tanto na forma do Fundo Soberano do Conhecimento (lei $\left.\mathrm{n}^{\circ} 13.240 / 2015\right)$, quanto dos fundos patrimoniais (lei no 13.800/2019). O termo "inovação" ganha força nas duas últimas versões, "para justificar os principais objetivos anunciados do programa: propiciar fontes adicionais de financiamento e incentivar o incremento da captação de recursos próprios pelas IFES.” (XIMENES; STUCHI; RODRIGUES, 2019, p. 65). Houve, ainda, a alteração nos eixos do programa, suprimindo o eixo gestão e dando maior amplitude ao eixo empreendedorismo e a inovação, que são, de fato, os fulcros principais do programa, e mantendo o eixo internacionalização.

\footnotetext{
4 Para a análise das versões do Future-se recomendamos a leitura de Leher (2019, 2020) e de Ximenes,
} Stuchi e Rodrigues (2019). Para uma análise da primeira versão, ver Sousa e Coimbra (2020).

1056 - Rev. Bras. Polít. Adm. Educ. - v. 37, n. 2, p. 1053 - 1070, mai./ago. 2021 
Em linhas gerais, o programa apresenta duas ideias-força: a primeira diz respeito à redução da participação do Estado no financiamento das universidades e institutos federais, que, por meio de "parcerias" com o setor privado, arregimentariam os recursos adicionais para sua manutenção, no que reside, segundo à concepção do programa, a ampliação da autonomia das instituições; e a segunda ideia, que se relaciona à primeira, incentiva a produção de produtos e serviços para o mercado, sob o argumento de aproximar as universidades das demandas da sociedade, tornando-as empreendedoras, competitivas e voltadas para o desenvolvimento de inovações, garantindo, assim, as fontes adicionais de recursos para seu funcionamento. Além disso, a utilização das estruturas e recursos físicos e humanos das universidades estaria à disposição dos parceiros privados, num movimento de privatização do público avalizado pelo próprio Estado, sem precedentes na história recente das universidades federais.

A redução do entendimento no tocante à autonomia universitária como autonomia financeira e não de gestão financeira, patrimonial, didática e científica, conforme se depreende do art. 207 da Constituição Federal de 1988, "é inconstitucional e pretende refuncionalizar as universidades, substituindo o dever do Estado no desenvolvimento institucional de suas autarquias e fundações públicas" (LEHER, 2019, s. p.). Enfim, segundo Ximenes, Stuchi e Rodrigues (2019, p. 66), "Em todas as versões, contudo, de forma mais ou menos explícita, o sentido de redução da autonomia didático-científica, administrativa e de gestão financeira e patrimonial das IFES se mantém."

Mesmo mediante forte reação das universidades, associações e entidades do meio científico ao longo do processo de consulta sobre as três versões do programa, o governo federal envia o projeto de lei do Future-se ( $\left.\mathrm{PLn}^{\circ} 3.076 / 2020\right)$ à apreciação legislativa em 27 de maio de 2020, num formato mais enxuto que as versões anteriores, embora não apresente alterações relevantes com relação ao conteúdo.

Os objetivos do programa (art. $1^{\circ}$ ) pressupõem a opção por um modelo de universidade mais voltado para as demandas externas e com uma cultura empreendedora, o que vai de encontro aos modelos de universidade, inspirados na tradição iluminista e se aproxima de perspectivas contemporâneas ${ }^{5}$, consideradas mais ágeis, flexíveis, permeáveis às influências externas e às demandas da sociedade, dando por pressuposto que as universidades são burocráticas, ineficientes e indiferentes às demandas externas.

5 Conforme consta nas exposições de motivos no PL, "O modelo atual de pesquisa nas universidades e nos institutos federais do Brasil é um modelo pesado e burocrático que não atende mais às necessidades do pesquisador, que perde tempo valioso de sua atividade em burocracia, enquanto deveria focar mais tempo na atividade finalística. Além disso, as instituições federais superiores de ensino devem estar mais abertas às experiências internacionais e atentas às necessidades da sociedade brasileira." 
No eixo "Pesquisa, desenvolvimento tecnológico e inovação", o termo "pesquisa" se reveste de um caráter utilitarista e pragmático, focando no atendimento prioritário das demandas externas, e sempre acompanhado dos termos "desenvolvimento e inovação", qualificando, a priori, o tipo de pesquisa que se pretende incentivar. Ficam claras as prioridades a serem conferidas à pesquisa nas universidades e institutos que aderirem ao programa. Este prevê que nas políticas de pesquisa, desenvolvimento e inovação sejam observadas as diretrizes das políticas nacionais de ciência, tecnologia e inovação e as prioridades temáticas definidas pelo Ministério da Ciência, Tecnologia, Inovações e Comunicações (MCTIC) ${ }^{6}$. Observa-se, desse modo, que serão excluídos do Future-se as áreas das ciências humanas e sociais, assim como a formação de professores (EVANGELISTA, 2019).

De acordo com Leher (2019), o programa desestimula a pesquisa básica, a reflexão sobre os problemas lógicos e epistemológicos da ciência, de respostas aos dilemas éticos-estéticos-políticos que afligem a sociedade, a reflexão filosófica e a criação artística, assim como a formação humanística dos estudantes, para além da formação para o trabalho e para o desenvolvimento de uma mentalidade empreendedora, adaptadas às instabilidades do mundo contemporâneo.

As medidas de incentivo à pesquisa, ao desenvolvimento tecnológico e à inovação devem estar alinhadas à legislação de incentivos à inovação e à pesquisa científica e tecnológica no ambiente produtivo, observados os requisitos para a fruição de incentivos e benefícios de qualquer natureza, o que consiste em uma interferência na autonomia da universidade quanto as suas políticas internas para a pesquisa.

Nas diretrizes do eixo (art. 18), fica bem clara a necessidade de refuncionalização das estruturas de pesquisa e da capacitação dos recursos humanos das universidades voltadas para os propósitos que a pesquisa deve assumir nos escopo do programa, como: a capacitação da comunidade acadêmica para atuar no núcleo de inovação tecnológica, na gestão de processos de inovação, na prospecção de projetos de pesquisa e inovação; facilitar meios de acreditação de infraestruturas de pesquisa junto às entidades e aos órgãos competentes, para o estabelecimento de parcerias ou para a prestação de serviços técnicos especializados com empresas e demais instituições que integram o Sistema Nacional de Ciência, Tecnologia e Inovação; e promover a cultura de estímulo à pesquisa tecnológica, à inovação, ao empreendedorismo e à proteção

6 A portaria $n^{\circ} 1.122 / 2020$, que estabelece como prioritários no âmbito no MCTIC, projetos de pesquisa, desenvolvimento e inovações voltados para cinco áreas de tecnologias: estratégicas, habilitadoras, de produção, para desenvolvimento sustentável, e para qualidade de vida.

1058 - Rev. Bras. Polít. Adm. Educ. - v. 37, n. 2, p. 1053 - 1070, mai./ago. 2021 
à propriedade intelectual por meio de capacitações, eventos e outros meios de difusão de conhecimento, com o objetivo de consolidar a capacidade da instituição de ensino na apropriação e na negociação de ativos intangíveis.

No eixo "empreendedorismo", suas diretrizes visam "apoiar a implantação e a consolidação de ambientes que promovam inovação, com foco no estabelecimento de parcerias com o setor empresarial, incluídos os parques e polos tecnológicos, as incubadoras e as start-ups" (art. 19, I). Além disso, prima pelo aprimoramento de "modelos de negócios" das universidades e institutos para que possam oferecer inovações que supram as demandas da sociedade. É reafirmado o fomento a projetos de pesquisa aplicada e projetos de inovação que estimulem a criação de start-ups (art. 19, VII), definindo uma prioridade a projetos de pesquisa de viés específico.

O PL aponta a oferta de conteúdos e atividades de empreendedorismo nas matrizes curriculares dos cursos técnicos, de graduação e de pós-graduação, nos termos do disposto na política institucional de inovação (art. 19, VI), interferindo diretamente nas políticas de ensino das universidades e institutos. O que se percebe é o reforço à lógica do empreendedorismo, que já está sendo fortemente fomentada nos currículos escolares em diversos níveis ${ }^{8}$. A ideia é que não devemos mais formar para o emprego, diante de um mercado de trabalho que se expande, cada vez mais, em direção ao trabalho informal, no qual deverão ingressar a maioria dos jovens que adentram na universidade, mas formar empreendedores que, desde a graduação, sejam responsáveis por prover a própria sobrevivência sem nenhuma salvaguarda ou estabilidade futura.

O PL não prevê nenhuma ação voltada para a expansão de vagas e inclusão no ensino superior. Apesar de nas exposições de motivos constar a preocupação com as taxas de conclusão nas IFES e IFs, não deixa claro que ações concretas são propostas no âmbito do programa para o enfrentamento dessa questão.

Com relação ao eixo "internacionalização" a proposta do programa é tornar a universidade brasileira cada vez mais globalizada. Para tanto, prevê o estímulo a mobilidade institucional de estudantes, técnicos-administrativos e de docentes entre as universidades participantes e universidades estrangeiras. Nesse caso, percebe-se grande destaque à pós-graduação, inclusive por meio de possibilidade de dupla titulação (double degree), titulação conjunta (joint degree) e cotutela de orientação, sem a necessidade de credenciamento ou autorização

$7 \quad$ "O termo é advindo do universo empresarial, mais especialmente voltados para startups, que são empreendimentos de base tecnológica com forte tendência a inovação, o modelo de negócios é a forma como a empresa cria, entrega e captura valor." (https://www.voitto.com.br/blog/artigo/modelo-de-negocio. Acesso em: 22 jun. 2020).

$8 \quad$ As Diretrizes Curriculares Nacionais para o Ensino Médio (portaria n $n^{\circ} 1.210 / 2018$ ) estabelecem o empreendedorismo como eixo estruturante para a organização dos itinerários formativos. 
específica. Como não especifica que tipo de instituição estrangeira poderá celebrar esses convênios, os limites e nem a necessidade de autorização prévia, abre-se um campo para a expansão de instituições estrangeiras, inclusive com fins lucrativos, para atuação no território brasileiro, fortalecendo o mercado educacional.

Tal fenômeno é analisado por Laval (2019) como uma tendência à constituição de uma rede de educação mundial, transfronteiriça e pós-nacional, sobretudo no âmbito da educação superior, fortalecendo um mercado global da educação, impulsionada pelo avanço das novas tecnologias da informação e comunicação e justificada pela necessidade de qualificação da mão de obra nacional para expandir a competitividade econômica dos países.

\begin{abstract}
Não há dúvida de que essa tendência pode pôr em xeque todas as estruturas do arcabouço nacional de educação, desde os princípios que regulam as obrigações dos alunos e das instituições até o valor dos diplomas concedidos em território nacional. Isso poderia abrir um mercado de formação superior e de diplomação dentro de um espaço mundial desregulamentado, fornecendo meios suplementares de imposição simbólica e dominação econômica a nações e empresas que já desenvolveram muito seu potencial educacional. (LAVAL, 2019, p. 136).
\end{abstract}

A participação no programa está condicionada à celebração de um "contrato de resultado", que deve ser firmado entre as universidades e institutos federais e o MEC, através de "estabelecimento de indicadores de resultado para a implementação de ações que abrangerão todos os eixos do Programa Future-se" $\left(\sqrt{ } 1^{\circ}\right.$, art. $\left.6^{\circ}\right)$, que serão definidos pelo MEC e pelo MCTIC, contemplando, em cada eixo, incrementos de eficiência e economicidade. O sistema de governança, controle e avaliação dos contratos deve ser criado em regulamento específico.

Entre os benefícios provenientes do contrato de resultado estão o recebimento de recursos orçamentários adicionais, consignados pelo MEC, e a concessão preferencial de bolsas da Capes às universidades e aos institutos federais participantes do programa $\left(\llbracket 2^{\circ}\right.$, art. $\left.6^{\circ}\right)$. Além de ser impreciso quanto ao montante de recursos adicionais a serem destinados para o financiamento das ações constantes do Contrato de Resultados, o PL é injusto quanto ao critério de distribuição de bolsas Capes, sobretudo no que diz respeito às áreas consideradas não prioritárias, asfixiando-as ainda mais.

No art. 30 do PL, os contratos de resultado somente poderão ser celebrados após a edição de portaria conjunta do Ministério da Economia e do MEC, a qual indicará a existência de dotação orçamentária, estimará o

\footnotetext{
9 A figura dos contratos de resultado assemelha-se ao contrato de gestão, instituído através da emenda constitucional no 19/1998 e consiste em ampliar a autonomia gerencial, orçamentária e financeira dos órgãos e entidades da administração direta e indireta, mediante contrato entre seus dirigentes e o poder público.
}

1060 - Rev. Bras. Polít. Adm. Educ. - v. 37, n. 2, p. 1053 - 1070, mai./ago. 2021 
impacto orçamentário e financeiro e atestará a compatibilidade do programa com a Lei Complementar n 101, de 4 de maio de 2000, com a Lei de Diretrizes Orçamentárias vigente e com as normas de direito financeiro e orçamentário aplicáveis. Isso torna incerta a existência de recursos para financiamento das ações desenvolvidas no âmbito do Future-se, apesar de o programa criar uma forte expectativa nesse sentido. No entanto, no art. 27 permite aos fundos patrimoniais apoiarem as ações do Programa Future-se, além de outros fundos patrimoniais específicos para universidades e institutos federais.

Para executar os contratos de resultado, as universidades e institutos poderão firmar contratos e convênios diretamente com fundações de apoio, devidamente credenciadas, nos termos da lei no 8.958/1994, que atuarão em projetos de produção, fornecimento e comercialização de insumos, produtos e serviços (art. 16). Prevê a comercialização de produtos ou serviços com as marcas das instituições e o excedente de produção resultante das atividades executadas no âmbito das universidades ou dos institutos federais. O PL também institui a flexibilização dos contratos trabalhistas via CLT, para a contratação de pesquisadores e professores de instituições estrangeiras por meio das fundações de apoio para prestar serviços no âmbito do Future-se.

Conforme o exposto, percebe-se que o Future-se tem por objetivo desenvolver uma nova lógica em relação à universidade e ao trabalho acadêmico. Reforça o senso comum de que o mercado deva dar forma à atividade acadêmica e aos produtos dela provenientes, seja com relação ao resultado da produção científica desenvolvida nas universidades, seja em relação ao tipo de profissional que ela forma. Isso altera o ethos de universalidade que caracteriza essa instituição, em sua multiplicidade de saberes e campos de investigação e atuação e o substitui "por um apêndice do setor [produtivo] ou da empresa que utiliza seus serviços de pesquisa e produção de mão de obra” (LAVAL, 2019, p. 101).

\section{ADESÃO À LÓGICA DO FUTURE-SE POR DENTRO DAS INSTITUIÇÕES: O CASO DA UFMA}

O debate sobre a adesão ao Future-se pelas universidades federais teve início imediatamente após seu lançamento, em julho de 2019, a fim de avaliar o conteúdo da proposta apresentada pelo MEC. Das 63 universidades federais, 27 se posicionaram contrárias ao Future-se, 7 têm posição crítica, 29 não informaram $\operatorname{posição~}^{10}$.

10 Disponível em: https://educacao.estadao.com.br/noticias/geral,maioria-das-universidades-federaisrejeita-Future-se,70003024425. Acesso em: 25 jun. 2020. 
Desde seu lançamento até o envio do projeto de lei ao legislativo, foram apresentadas três propostas e decorreram 11 meses. Nesse interstício, a administração superior da UFMA tem se antecipado, adotando os princípios e implementado ações em direção à concepção do programa, conforme analisaremos em seguida.

Considerando a rejeição que o programa tem enfrentado nas universidades federais onde já foi apreciado, a estratégia de adaptar a universidade aos seus princípios e diretrizes - sem o necessário debate com a comunidade acadêmica -, por meio de implantação de políticas e da reestruturação dos setores, parece ter sido a maneira encontrada pela administração superior da UFMA para minar resistências e implementar as diretrizes do Future-se sem maiores sobressaltos.

O processo de reestruturação de setores importantes da universidade, a exemplo da antiga Pró-Reitoria de Pesquisa, Pós-Graduação e Inovação (PPPGI), que agrega as funções estratégicas no âmbito do Future-se, pois concentra as políticas de pesquisa, desenvolvimento e inovação, empreendedorismo e internacionalização, corrobora a hipótese apresentada neste texto de que há uma convergência tácita com os princípios e diretrizes do programa na atual gestão da UFMA. Rebatizada como Agência de Inovação, Empreendedorismo, Pesquisa, Pós-graduação e Internacionalização (AGEUFMA), “tem por finalidade planejar, orientar, executar, coordenar e supervisionar as atividades de Inovação Tecnológica, Pesquisa, Pós-Graduação, Empreendedorismo e Internacionalização no âmbito da UFMA", tendo como destaque desenvolver ações que "potencializem a capacidade empreendedora e de inovação da comunidade acadêmica, proporcionando soluções e serviços à sociedade."11

Entre suas diretrizes, conforme descrito no site oficial, constam:

Difundir a cultura de inovação tecnológica e proteger a propriedade intelectual da Universidade Federal do Maranhão por meio da capacitação tecnológica, registro, licenciamento e transferência de tecnologias; Articular parcerias estratégicas com empresas públicas, privadas ou setores governamentais, para o desenvolvimento de projetos e serviços científico-tecnológicos; Promover ações institucionais de capacitação de recursos humanos em empreendedorismo e estimular o processo de pré-incubação e incubação de empresas inovadoras de base tecnológica; Promover a cultura do empreendedorismo no meio acadêmico, bem como apoiar e acompanhar as Empresas Juniores da UFMA; Estruturar o Parque Tecnológico da UFMA, visando expansão da inovação e do empreendedorismo e a interação entre os setores públicos, universidades e empresas.

11 Disponível em: https://portais.ufma.br/PortalProReitoria/ageufma/paginas/pagina_estatica. jsf ?id=238. Acesso em: 23 abr. 2020. 
O Empreendedorismo ${ }^{12}$ passou a ser um dos setores com maior destaque na AGEUFMA. Na visão do chefe da Diretoria de Empreendedorismo (DEMP), a relação do empreendedorismo com a pesquisa e a inovação deverão trazer excelentes índices de qualidade para a universidade. "É impossível pensar a desarticulação entre as áreas. Quando o empreendedorismo está fora desse ecossistema, a gente fica com dificuldade de captar ideias e recursos, que se tornarão capitais intelectuais, considerando que ideias se transformam em oportunidades, e oportunidades em negócios." (Grifos nossos) ${ }^{13}$.

As ações da AGEUFMA no sentido de adaptar a universidade a uma “cultura empreendedora", conforme advogado pelo Future-se, já estão em andamento. A exemplo do "Mapeamento de competências para prospecção de oportunidades UFMA 2020", realizado pela Diretoria de Gestão da Inovação e Serviços Tecnológicos (DGIST) da AGEUFMA, que, por meio de um formulário enviado a todos os docentes e servidores da UFMA, pretende "realizar o mapeamento das competências da nossa instituição, visando divulgar os conhecimentos e competências da UFMA para a transferência de tecnologias e para a prestação de serviços inovadores que contribuirão para o desenvolvimento científico e tecnológico da região."14 Tal formulário deveria ser respondido por pesquisadores, coordenadores de laboratórios e de grupos de pesquisa para descrever suas competências com potencial de solucionar demandas qualificadas de mercado.

Através de um e-mail ${ }^{15}$ enviado para o setor, solicitando maiores esclarecimentos sobre a natureza e as finalidades do mapeamento, recebemos como resposta algumas informações que elucidam o foco com o qual será conduzida a pesquisa na instituição, revelando a intenção de criar, de fato, uma cultura empreendedora e de aproximação às demandas do setor privado, conforme delineado pelo Future-se. Em resposta ${ }^{16}$, o diretor da DGIST, que

12 Na estrutura anterior da universidade, as ações direcionadas ao empreendedorismo, notadamente incubação de empresas e criação de empresas júniores, estavam sob a responsabilidade da Pró-Reitoria de Extensão, Cultura e Empreendedorismo, onde também estava localizado o Centro de Empreendedorismo da UFMA (CEU). O fato de integrar essas ações no âmbito da AGEUFMA já deixa clara a intenção de implementar as diretrizes e eixos do programa Future-se de forma coordenada através dessa agência, dando maior organicidade às ações de pesquisa e desenvolvimento, empreendedorismo e inovação.

13 Disponível em: https://portais.ufma.br/PortalProReitoria/ageufma/paginas/noticias/noticia. jsf?id=55383. Acesso em: 28 jun. 2020.

14 Memorando eletrônico $\mathrm{n}^{\circ}$ 5/2020 DGIST/AGEUFMA, de 11/04/2020. O formulário pode ser acessado em: https://docs.google.com/forms/d/e/1FAIpQLSdi-P8mL42YjxH0xy2yWA2gZae0b07PBJ0qHy4yf3f8WlLuQ/viewform?usp=sf_link.

15 SOUSA, A. P. R. de. Informações sobre o mapeamento de competências [mensagem pessoal]. Mensagem recebida por<ageufma.dist@ufma.br> em 14/04/2020.

16 LIMA, S. RE: Informação sobre o mapeamento de competências [mensagem pessoal]. Mensagem recebida por<anapaularis@hotmail.com> em 14/04/2019. 
assina o e-mail, deixa bem claro que a diretoria "tem como carro-chefe permitir, incentivar, auxiliar e dar agilidade aos processos que envolvam convênios entre $\mathrm{o}$ setor público, privado e sociedade civil que tenha como objetivo trazer recursos para a universidade." Ou seja, a estratégia de autofinanciamento, conforme previsto pelo Future-se, no sentido de reduzir a participação do fundo público, é apontada como o principal propósito do setor.

E uma das formas de trazer esses recursos, de acordo com a resposta do diretor da DGIST/AGEUFMA, é por meio de projetos com empresas, onde a universidade recebe participação, a exemplo do que ocorre atualmente nas áreas de ciências exatas e tecnológicas. Contudo, ressalta que as demandas do setor privado têm que ser atendidas com agilidade e eficiência, o que muitas das vezes fica a desejar devido a "problemas internos para atuar nesse campo", apontados como uma das dificuldades de se estabelecer relação com as empresas, a exemplo dos trâmites burocráticos necessários para a formalização de convênios com a iniciativa privada para a execução de projetos em parceria com departamentos e laboratórios da universidade, que pode levar até um ano e fazer com que a instituição não seja competitiva.

A segunda forma de atrair recursos privados para a universidade, segundo o diretor da DGIST, seria por meio de prestação de serviços tecnológicos em diversas áreas (cursos lato sensu, laudos, assessorias, entre outros), a serem oferecidos pelos profissionais e utilizando recursos da universidade (infraestrutura, laboratórios e equipamentos). Nessa ação, se insere o formulário de mapeamento de competências para prospecção de profissionais que tenham interesse em realizar a prestação de serviço, além de equipamentos e laboratórios da universidade que podem ser utilizados para esse fim, em conformidade com a legislação vigente. De acordo com o que foi esclarecido pelo e-mail, essa seria uma primeira fase, "posteriormente a essa prospecção que terá uma segunda etapa em campo, visitando os professores, pretendemos disponibilizar os dados em uma página web da UFMA, um portfólio de serviços tecnológicos e os procedimentos para a contratação."

O diretor acrescenta que estão sendo elaboradas duas normativas direcionadas aos dois temas no âmbito da UFMA: "a primeira, que trata da relação da UFMA com as Fundações de Apoio, permitindo maior agilidade e cobrança na execução séria e profissional dos projetos e a segunda que trata da prestação de serviços".

Além disso, o diretor da DGIST apresenta a preocupação com os equipamentos e estruturas da UFMA que se encontram subutilizados pelos pesquisadores, o que, segundo ele, seria um desperdício do recurso público, ao invés de produzir resultados para a sociedade. Contudo, parece ignorar que os 
recursos públicos para a ciência e tecnologia, que financiam grande parte da pesquisa em nosso país, estão sendo sistematicamente reduzidos ${ }^{17}$, inviabilizando, por exemplo, a compra de materiais e pagamento de bolsas para pesquisadores para realização de pesquisas relevantes com os equipamentos e recursos existentes nas universidades.

Percebemos que essa lógica passa a ser imposta ao trabalho docente na universidade. Para produzir, o pesquisador deve "vender" o seu produto no mercado, para que tenha possibilidades de arcar com o ônus de sua própria atividade, já que o financiamento público para ciência e tecnologia e para as universidades estão sendo sistematicamente reduzidos. Nesse contexto, segundo Leher (2019), o Future-se pretende profundas alterações na natureza do trabalho docente, pois "Instaura um ethos empreendedor que sinaliza benefícios para os que priorizarem as atividades de P\&D e de serviços, indicando que esse é o caminho a seguir, especialmente aos jovens."

Outras ações promovidas pela AGEUFMA, direcionadas ao fortalecimento do empreendedorismo, caminham na perspectiva do Future-se, como a palestra "Startups: a universidade transformando ciência em soluções de mercado", realizada pela DEMP, com o prof. Dr. Rômulo Martins, cofundador da Niduu (startup de gerenciamento de pessoas) e professor da UFMA, no sentido de estimular o comportamento empreendedor entre o corpo docente e dar visibilidade a essa atividade agregada ao trabalho acadêmico ${ }^{18}$.

Outra ação direcionada nesse sentido é o "Business Talke", também promovido pela DEMP. Lançado em março de 2020, a ideia é que o evento seja realizado em várias unidades da UFMA, com o objetivo de discutir sobre startups, empresas juniores, o universo do empreendedorismo e divulgar o Centro de Empreendedorismo de Inovação da UFMA (CEI). Nos encontros serão discutidos três temas: "Empreendedorismo"; "Da ideia ao negócio: conheça o CEI"; e "O que é uma startup?" - com foco na discussão do mundo do empreendedorismo e suas inovações e oportunidades, com presença de discentes, docentes e empresários ${ }^{19}$.

17 No Brasil, o orçamento para a área de ciência e tecnologia vem progressivamente diminuindo. Em 2013, o orçamento do Ministério da Ciência e Tecnologia foi de R \$ 9,5 bilhões; em 2019, o orçamento foi de, aproximadamente, $\mathrm{R} \$ 3$ bilhões - uma queda de mais de $60 \%$, sendo $42 \%$ só em 2019 . Como o grosso da pesquisa no Brasil é financiado com recursos públicos e desenvolvido por instituições públicas, esses cortes refletem diretamente nas condições de realização de pesquisas nas universidades federais.

Disponível em: https://www1.folha.uol.com.br/ciencia/2019/04/corte-orcamentario-de-42-em-ciencia-etecnologia-preocupa-entidades.shtml e https://www.andes.org.br/conteudos/noticia/orcamento-da-educacaosofre-corte-de-r-5-83-bilhoes1. Acesso em: 30 abr. 2020.

18 Live realizada no Instagram da AGEUFMA, em 11 de junho de 2020. Disponível em: https:// portais.ufma.br/PortalProReitoria/ageufma/paginas/noticias/noticia.jsf?id=56391. Acesso em: 26 jun. 2020.

19 Disponível em: https://portais.ufma.br/PortalProReitoria/ageufma/paginas/noticias/noticia. jsf?id=55843. Acesso em: 26 jun. 2020. 
Diante do exposto em relação à apropriação das diretrizes do Futurese na UFMA e nas demais universidades no país, questiona-se o impacto sobre a pesquisa básica, a pesquisa nas áreas de ciências humanas, sociais, artísticas, linguísticas, filosófica, que não geram resultados imediatos por meio de produtos e processos que possam atender aos interesses do mercado por soluções tecnológicas e inovações. Considera-se que, se a implementação do Futurese lograr êxito mediante a aprovação do PL e a adesão das universidades ao programa, é muito provável que estas sejam postas à margem das modalidades de financiamento disponíveis no programa, enfraquecendo a posição dessas áreas.

Avalia-se que isso gerará um clima de competitividade entre os pesquisadores na disputa por recursos para realizar suas pesquisas, prestar serviços, desenvolver produtos e garantir uma eventual complementação salarial, gerando uma fragmentação ainda maior na categoria do magistério universitário, entre os "produtivos" e os "improdutivos". Ainda constata-se que a adesão ao Future-se configura uma restrição da autonomia universitária, em função da necessidade de atender demandas externas, quanto à pesquisa e inovação e a prestação de serviços, assim como a autonomia em relação ao ritmo da pesquisa e da produção científica diante das exigências em atender, de forma mais eficiente, às demandas do mercado.

No limite, considera-se que a função pública da universidade restaria ameaçada diante da pressão para dar suporte, por meio da pesquisa e da prestação de serviços, a demandas privadas e atrair recursos para a universidade, solapando os critérios democráticos para o acesso a recursos para a realização de pesquisas na universidade em áreas que tenham relevância social, mas não despertam o interesse do mercado.

Estas questões seguem em aberto ou, pelo menos, temos como hipótese que se a UFMA e as demais universidades seguirem as trilhas indicadas pelo Future-se, provavelmente teremos um forte direcionamento para a alteração do ethos acadêmico na universidade, descaracterizando o papel historicamente desempenhado por essa instituição, fragilizando ainda mais a sua autonomia e estabelecendo critérios cada vez mais vinculados à produtividade para reconhecimento do mérito acadêmico.

\section{CONSIDERAÇÕES FINAIS}

Boaventura de Sousa Santos (2020), em texto sobre os desafios à universidade pública, afirma: que poucas instituições estarão tão ameaçadas, mas nenhuma outra será tão necessária. Tal frase coloca em evidência a contradição da universidade no mundo contemporâneo. Historicamente, a universidade foi 
construída como um espaço que visa a conservação e difusão do conhecimento cultural acumulado pela humanidade e de investigação profunda dos problemas dos povos, que não se restringem e se limitam a um tempo estabelecido ou a uma situação prática, embora parta efetivamente deles, mas se caracteriza como universal. E esse papel é reconhecido pelas expectativas direcionadas à universidade na busca de soluções para os problemas que afligem a humanidade. Nesses tempos de pandemia, essa expectativa se expressa na busca de vacinas e tratamentos para o vírus, quando todos os olhares são voltados para as instituições de pesquisa, entre elas, a universidade.

Ao mesmo tempo, a produção do conhecimento sob a lógica do capitalismo, que podemos, com Laval (2019), chamar de "utilitária", direcionase à solução de problemas diretamente relacionados à prática, no seu sentido mais imediato, pragmático e geralmente instrumentalizado, ignora a dimensão universal do saber e das especificidades do processo de produção desse saber. Nesse sentido, o mundo da produção "coloniza" o espaço-tempo universitário. Por isso, talvez, algumas pesquisas que visam diretamente apresentar soluções pragmáticas para a sociedade, muitas vezes com interesses mercadológicos, não respeitando o tempo e o desenvolvimento da pesquisa científica, podem atropelar tal processo e enviesar os resultados da investigação, comprometendo-os, tanto do ponto de vista científico, quanto do ponto de vista ético.

Nesse sentido, Laval (2019) identifica, assim como o faz Sousa Santos (2020), que o capitalismo universitário tem sido uma das ameaças globais que pairam sobre a universidade pública, que se intensificou nos últimos 40 anos, a partir da hegemonia do neoliberalismo como lógica dominante do capitalismo global.

De modo geral, um novo campo de acumulação do capital surge com a transformação das universidades em fábricas de saber eficiente. A produção de conhecimentos e do próprio saber são moldados pelo "capitalismo universitário". $\mathrm{Na}$ verdade, toda a cadeia de produção de conhecimentos tende a se transformar de acordo com os imperativos da valorização do capital. (LAVAL, 2019, p. 57).

Uma consequência desse fenômeno, segundo Sousa Santos (2020), é que as universidades passam a ser concebidas como um investimento lucrativo, de modo que lhes seja permitida a busca de receitas próprias no mercado e a adoção de critérios empresariais de gestão, baseados na eficiência, eficácia, flexibilidade, satisfação do cliente e produtividade. Desse modo, as universidades públicas devem se tornar competitivas e integrar os rankings dos sistemas globais de avaliação para aferir "objetivamente" seu valor de mercado. 
Essa perspectiva ganhou terreno ao longo das últimas décadas, tendo o modelo americano como epicentro e, posteriormente, exportado para a Europa e outras regiões de capitalismo desenvolvido (LAVAL, 2019). As consequências desse movimento são diversas e matizadas, e vão desde processos de hibridização universidade-empresa, de modo que não se distingue claramente os interesses comerciais dos científicos, comprometendo a autonomia e os limites éticos da pesquisa, a facilitação da apropriação e transferência comercial dos conhecimentos e o esvaziamento de algumas atividades que integram o fazer universitário, como o ensino, em detrimento da pesquisa, que gera resultados comercializáveis.

Por outro lado, segundo Sousa Santos (2020), a "guerra cultural" perpetrada contra as universidades pela ultradireita, vendo-as como centros de produção e difusão de ideologias de esquerda - abrigadas sobre a terminologia genérica de "marxismo cultural" -, justificam o ataque contra o pensamento crítico, livre e independente que, segundo essa ótica, visa subverter as instituições e desestabilizar a ordem social. Por isso, devem ser amordaçadas, docilizadas e reprogramadas para operar de acordo com a lógica pragmática, extirpando do fazer acadêmico toda e qualquer ideologia ameaçadora. Isso implica em remover dos currículos universitários todo e qualquer conhecimento que não seja diretamente "útil" à formação na perspectiva do mercado e todo o conteúdo ideológico que se contraponha à ideologia dominante.

A nosso ver, o Future-se condensa essas duas dimensões do ataque neoliberal às universidades públicas brasileiras, pois ao mesmo tempo em que as torna funcionais ao capitalismo, esteriliza, por inanição, seu potencial crítico, o que representa o projeto das forças ultraliberais conservadoras que ocupam o poder político no Brasil atualmente. Isso pode ser claramente percebido nas linhas gerais do programa, que se direcionam para a pesquisa direcionada a resultados diretamente aplicáveis, que gere inovações para o setor produtivo e promova o empreendedorismo como valor agregado à cultura universitária.

Apesar de não ter sido objeto desta investigação, podemos levantar a hipótese de que esse movimento de receptividade aos princípios e diretrizes contidos no Future-se agrade alguns segmentos da comunidade acadêmica, e se observe algo parecido em outras universidades brasileiras, pois, além do Futurese, já existe um arcabouço regulatório e legislativo fértil nesse sentido.

Portanto, é preciso evocar a função social e pública da universidade, expor os ataques perpetrados à universidade pública de gestão pública, por meio dos cortes tanto de seus orçamentos próprios, quanto dos recursos destinados para a área de ciência e tecnologia, que também abastecem as universidades federais. Ao mesmo tempo, é necessário reafirmar sua relevância, tendo em vista que, apesar de todas as restrições e críticas, são as instituições que mais se destacam 
no combate à pandemia, seja na pesquisa de fármacos, vacinas, tratamentos, seja na assistência, no monitoramento epidemiológico e na pesquisa social sobre suas implicações.

\section{REFERÊNCIAS}

BRASIL. Câmara dos Deputados. Projeto de lei $n^{\mathbf{0}}$ 3076/2020. Institui o Programa Universidades e Institutos Empreendedores e Inovadores - Future-se. Disponível em: https://www.camara.leg.br/proposicoesWeb/prop_mostrarinteg ra;jsessionid $=$ EB1062A5AA5D3BDB3E4112E8A52B723B.proposicoesWebEx terno1?codteor $=1900012 \&$ filename $=P L+3076 / 2020$. Acesso em: 15 jun. 2020.

DARDOT, Pierre; LAVAL, Christian. A nova razão no mundo: ensaio sobre a sociedade neoliberal. São Paulo: Boitempo, 2016.

EVANGELISTA, Olinda. Por que o Future-se abjurou a formação docente? UFSC à esquerda. Florianópolis, 29 set. 2019. Disponível em: https:// ufscaesquerda.com/por-que-o-Future-se-abjurou-a-formacao-docente/. Acesso em: 10 jun. 2020.

FRIGOTTO, Gaudêncio. Método materialista histórico-dialético como instrumento de análise da realidade. In: TULESKI, Silvana Calvo; FRANCO, Adriana de Fátima; CALVE, Tiago Morales (Org.) Materialismo históricodialético e psicologia histórico-cultural: expressões da luta de classes no interior do capitalismo. Paranavaí: EduFatecie, 2020. p. 15-35.

LAVAL, Christian. A escola não é uma empresa: o neoliberalismo em ataque ao ensino público. São Paulo: Boitempo, 2019.

LEHER, Roberto. "Future-se" indica a refuncionalização das universidades e institutos. Federais. Le Monde Diplomatique Brasil, 2 ago. 2019. Disponível em: https://diplomatique.org.br/Future-se-indica-a-refuncionalizacao-dasuniversidades-e-institutos-federais/. Acesso em: 15 maio 2020.

LEHER, Roberto. Esboço de análise sobre o Projeto de Lei do Future-se. Le Monde Diplomatique Brasil, 17 jun. 2020. Disponível em: https:// diplomatique.org.br/projeto-de-lei-do-future-se/. Acesso em: 20 jun. 2020. 
MORAES, Roque. Análise de conteúdo. Revista Educação. Porto Alegre, v. 22, n. 37, p. 7-32, 1999.

SANTOS, Boaventura de Sousa. A universidade pós-pandêmica. Boletim Outras Palavras, 7 jul. 2020. Disponível em: https://outraspalavras.net/ alemdamercadoria/boaventura-a-universidade-pos-pandemica/. Acesso em: 8 jul. 2020.

SOUSA,A.P.R. de;COIMBRA,L.J.P. Future-se: um golpe contra a democratização do ensino superior. Jornal de Políticas Educacionais, v. 14, n. 12, jan. 2020. Disponível em: https://revistas.ufpr.br/jpe/article/download/69548/40314. Acesso: 30 maio 2020.

XIMENES, Salomão; STUCHI, Carolina Gabas; RODRIGUES, Rayane Vieira. O passado do Future-se: análise de conteúdo de três versões preliminares do programa. In: XIMENES, Salomão; CÁSSIO, Fernando (org.). Future-se? Impasses e perigos à educação superior pública brasileira. Santo André: Fórum Permanente de Políticas Educacionais da UFABC, Universidade Federal do ABC, 2019. p. 52-67

\section{Ana Paula Ribeiro de Sousa}

Doutora em Educação pela UFF. Mestre em Educação pela UFMA. Graduação em História pela UFMA. Professora da Universidade Federal do Maranhão. E-mail: anapaularis@hotmail.com

\section{Leonardo José Pinho Coimbra}

Doutor em Educação pela UFF. Mestre em educação pela UFMA. Graduação em História pela UFMA. Professor da Universidade Federal do Maranhão. E-mail: solidsnk@bol.com.br 